\title{
Mycoplasma Pneumoniae and Chlamydia Pneumoniae Seropositivity in Patients With Age-Related Macular Degeneration
}

\author{
Burak Turgut $^{\mathrm{a}, \mathrm{c}}$, Fatma Uyar ${ }^{\mathrm{a}}$, Fulya Ilhan ${ }^{\mathrm{b}}$, Tamer Demir ${ }^{\mathrm{a}}$, Ulku Celiker ${ }^{\mathrm{a}}$
}

\begin{abstract}
Background: To determine a possible relation between Mycoplasma pneumoniae (MP) or Chlamidia pneumoniae (CP) seropositivity and age-related macular degeneration (AMD).

Methods: Sixty patients (20 wet AMD, 20 dry AMD and 20 nonAMD controls) were included in the study. Serum samples were collected for analysis of $\operatorname{IgM}$ and $\operatorname{IgG}$ antibody seropositivity for $\mathrm{CP}$ and MP by enzyme-linked immunosorbent assay (ELISA). Comparison of the distribution of seropositivity of these antibodies among patients with wet and dry AMD, and controls was performed. A prospective comparative clinical trial was applied.
\end{abstract}

Results: There was no major difference in the distribution of IgM and $\mathrm{IgG}$ seropositivity to $\mathrm{CP}$ and $\mathrm{MP}$ in patients with wet and dry $\mathrm{AMD}$, and in controls $(\mathrm{p}>0.05)$.

Conclusions: We found no significant association between MP as well as CP antibody titers and AMD. It seems that MP or CP infection is not a risk factor for AMD.

Keywords: Mycoplasma pneumoniae; Chlamydia pneumoniae; Age-related macular degeneration; Serology

\section{Introduction}

Age-related macular degeneration (AMD) is a major cause of irreversible visual loss in developed countries in 65 years

\footnotetext{
Manuscript accepted for publication March 24, 2010

${ }^{a}$ Firat University School of Medicine, Department of Ophthalmology, Elazig, Turkey

${ }^{\mathrm{b}}$ Firat University School of Medicine, Department of Immunology, Elazig, Turkey

${ }^{\mathrm{c} C o r r e s p o n d i n g ~ a u t h o r, ~ E-m a i l: ~ d r b u r a k t u r g u t @ y a h o o . c o m ~}$
}

doi:10.4021/jocmr2010.03.282w and older. Although the pathogenesis of AMD is not clearly understood, it has been considered that AMD is multifactorial disease. Risk factors associated with AMD include smoking, diet, light exposure, advanced age, race, family history (genetics), body mass index, underlying cardiovascular disease, and systemic inflammatory or infectious diseases [1-3]. A number of clinical and experimental studies also suggest a role for inflammation or infection. The potential role of infectious agents as a trigger for inflammation in the pathogenesis of AMD as well as systemic vascular diseases is a subject of continuing debate [4-6].

In recent studies, Cytomegalovirus (CMV), Chlamydia pneumoniae (CP), and Helicobacter pylori (HP) have been linked to AMD. The link between CP and AMD is still controversial. Kalayoglu et al have demonstrated the presence of $\mathrm{CP}$ in choroidal neovascular membranes (CNVM) related with AMD and the serological association between CP infection and AMD $[7,8]$ whilst in two recent studies, Robman et al and Kessler et al failed to show an association between CP and AMD or AMD CNVM, respectively [9, 10]. There is no data in literature concerning the association between AMD pathogenesis and Mycoplasma pneumonia (MP), another atypical bacterium.

Mycoplasmas, which are the smallest and simplest selfreplicating microorganisms, can exist as a persistent asymptomatic infection, resulting in chronic inflammation as well as $\mathrm{CP}[11,12]$. MP is a significant respiratory pathogen in persons of all ages, causing respiratory disease, and it may induce clinically significant manifestations in extra-pulmonary sites by direct invasion and/or immunologic effects. Macrophage activation, cytokine induction, and super-antigen properties are some factors related to the pathogenity of Mycoplasmas [11-14]. In recent studies, the association of MP and CP has been described in pneumonia, astma, aortic stenosis, coronary atherosclerosis, and stroke or in immunodeficient patients [15-20]. In addition, it is considered that co-infections with CP in association with MP potentiate the virulence of both agents. Therefore, when circulating antibodies of both these two agents are present in patients with AMD, they may increase each other's pathogenicity [21,22].

Therefore, we hypothesized that infection or postinfection with MP may be associated with AMD and we purposed 
to determine this possible association.

\section{Patients and Methods}

This pilot study was designed as a prospective case-control study and 20 patients with dry AMD (Group 1), 20 patients with wet AMD (Group 2) and 20 subjects age- and sexmatched and without AMD (Group 3) were included in the study. All patients underwent a complete ophthalmologic and general examination. The protocol for the study was reviewed and approved by the institutional review board. The tenets of the Helsinki declaration were followed throughout the study. Informed consent was obtained from each subject including detailed explanation of all procedures before participation in the study. A staff retina specialist classified AMD into nonneovascular or neovascular stages of disease.

\section{Inclusion criteria}

In group 1, the patients with dry (nonneovascular) AMD characterized by macular drusen or the presence of geographic atrophy without choroidal neovascularization (NV) or scarring documented by color fundus imaging, Fundus Fluorescein Angiography (FFA) and Optic Coherence Tomography (OCT).

In group 2, the patients with wet AMD with CNVM or disciform scar documented by FFA and OCT.

In group 3, control subjects that are sex- and agematched subjects included patients presenting for routine eye examination with or without other ocular disorders, but without evidence of drusen, retina pigment epithelial changes or choroidal neovascularization.

The participants with diabetes mellitus, ocular or systemic infection and inflammation, any hematological and immune disease, malignancy, hypergammaglobulinemia, connective tissue disease, history of myocardial infarction and coronary artery disease, or history of the usage of the drug that could influence serum immunoglobulin levels and previous laser treatment or intravitreal injection were excluded from the study.

\section{Serological assay}

Peripheral venous blood $(10 \mathrm{ml})$ was collected from patients and healthy controls by venipuncture. The serum was separated and stored frozen at $-20^{\circ} \mathrm{C}$. Samples were encoded, and laboratory personnel were masked to clinical information on the patients. Serological analysis as described in the following subsections was made by same personnel.

Qualitative immunoenzymatic determination of human $\mathrm{CP}$ IgG and IgM in serum were made using Novatec/Immunodiagnostica GmbH Germany (product No: CHLM0070, CHLG0070) on automatised ELISA system. Microtiter strip wells are precoated with $\mathrm{CP}$ antigens to bind corresponding antibodies of the specimen. After washing the wells to remove all unbound sample material horseradish peroxidase (HRP) labeled anti-human IgG (IgM) conjugate is added. This conjugate binds to the captured Chlamydia specific antibodies. The immune complex formed by the bound conjugate is visualized by adding tetrametilbenzidine substrate which gives a blue reaction product. The intensity of this product is proportional to the amount of Chlamydia specific $\operatorname{IgG}(\operatorname{IgM})$ antibodies in the specimen. Sulphuric acid is added to stop the reaction. This produces a yellow endpoint color. Absorbance at $450 \mathrm{~nm}$ infrared was read using an ELISA micro well plate reader.

The absorbance of all wells at $450 \mathrm{~nm}$ was measured and the absorbance values for each control and patients samples was recorded for identification absorbance distribution. The cut-off value was calculated according to absorbance value. Samples were considered positive if the absorbance value is higher than $10 \%$ over the cut-off. All results were given as a NovaTec Units (NTU) (Cut-off:10 NTU).

Quantitative tests for detection of human antibodies IgG and IgM in serum against MP (Virion/Serion GmbH Germany (product No: ESR127G and ESR127M) ELISA kit.

Antibodies activities were given in U/ml. For MP IgG calculation was interpreted positive results $>30 \mathrm{U} / \mathrm{ml}$, borderline results $20-30 \mathrm{U} / \mathrm{ml}$ and negative results $<20 \mathrm{U} / \mathrm{ml}$, and for IgM was positive results $>17 \mathrm{U} / \mathrm{ml}$, borderline results $13-17 \mathrm{U} / \mathrm{ml}$, negative results $<13 \mathrm{U} / \mathrm{ml}$. All ELISA reactions were performed according to manufacturer's instructions on Dynex 1DXC-1381 (USA) full automatic ELISA system.

\section{Statistical analysis}

Statistical analysis was performed using the Statistical Package for the Social Sciences version 13.0 (SPSS, Inc., Chicago, IL, USA). The Student t test or chi-square test was used to compare nominal and categorical variables among the study groups, respectively. Results were given as means \pm standard deviations. $P$ value less than 0.05 was considered as statistically significant.

\section{Results}

The subjects included 13 men (65\%) and 7 women $(35 \%)$ in Group $1 ; 12$ men $(60 \%)$ and 8 women (40\%) in Group 2; 10 men $(50 \%)$ and 10 women (50\%) in Group 3. The mean ages of the Group 1, Group 2 and Group 3 were $68.9 \pm 4.99$ years (range, 56 to 78 years), $65.85 \pm 4.91$ years (range, 58 to 74 years), $66.50 \pm 4.84$ years (range, 55 to 80 years), respectively. The patient and control groups were matched for age and sex and there was no statistically significant difference with regard to age and gender among the groups $(p>0.05)$. The demographical data in the study groups are shown in Table 1. 
Table 1. Demographical Data in the Study Groups

\begin{tabular}{lll}
\hline Group (n) & Mean Age (range) & Gender (\%) \\
\hline Dry AMD (20) & $68.90 \pm 4.99$ years $(56-78)$ & 13 men $(65 \%), 7$ women $(35 \%)$ \\
Wet AMD (20) & $65.85 \pm 4.91$ years $(58-74)$ & 12 men $(60 \%), 8$ women $(40 \%)$ \\
Non-AMD controls $(20)$ & $66.50 \pm 4.84$ years $(55-80)$ & 10 men $(50 \%), 10$ women $(50 \%)$ \\
\hline
\end{tabular}

None of 60 patients in the study groups had positive for Ig M antibody titers to CP. Two (10\%) of 20 patients with wet AMD had positive for IgG antibody titers to CP, compared with none of 20 patients with dry AMD and none of 20 controls. There was no major difference in the distribution of $\operatorname{IgM}$ and $\operatorname{IgG}$ titers for CP in wet and dry AMD ( $\mathrm{p}>0.05)$.

Similarly, there was no major difference in the distribution of IgM and IgG titers for MP in wet and dry AMD, and in controls $(p>0.05)$. All of the patients with wet AMD and dry AMD had negative for IgM antibody titers to MP whilst 19 (95\%) of 20 controls had negative. Borderline IgM titers to MP were only one in the controls. One (5\%) of 20 patients with wet AMD had positive for $\mathrm{IgG}$ antibody titers to MP, compared with two (10\%) of 20 dry AMD patients. One $(5 \%)$ of 20 controls had positive. Borderline IgG titers to MP were observed in three patients $(15 \%)$ in wet AMD group but only one (5\%) in each of dry AMD and control group. IgM and IgG seropositivities to $\mathrm{CP}$ and MP in the study groups are shown in Table 2.

The mean serum IgM titers for CP in patients with dry AMD (Group 1), wet AMD (Group 2) and in the controls (Group 3) were $2.09 \pm 1.56,1.27 \pm 1.18$ and $1.48 \pm 0.53$ $\mathrm{NTU} / \mathrm{mL}$, respectively. The mean serum $\mathrm{IgG}$ titers for $\mathrm{CP}$ in patients with dry AMD (Group 1), wet AMD (Group 2) and in the controls (Group 3) were $5 \pm 4.72,4.29 \pm 3.51$ and $3.30 \pm 2.06 \mathrm{NTU} / \mathrm{mL}$, respectively. There was no significant difference among the serum $\operatorname{IgM}$ and $\operatorname{IgG}$ titers of the study groups $(\mathrm{p}>0.05)$.

The mean serum IgM titers for MP in patients with dry AMD (Group 1), wet AMD (Group 2) and in the controls (Group 3) were $3.13 \pm 1.03,4.13 \pm 1.99$ and $4.13 \pm 2.63$ $\mathrm{mlU} / \mathrm{mL}$, respectively. The mean serum IgG titers for MP in patients with dry AMD (Group 1), wet AMD (Group 2) and in the controls (Group 3) were 9.95 $\pm 9.89,12.99 \pm 8.75$ and $15.78 \pm 8.32 \mathrm{U} / \mathrm{mL}$, respectively. There was no significant difference among the serum $\operatorname{IgM}$ and $\operatorname{IgG}$ titers of the study groups $(\mathrm{p}>0.05)$.

\section{Discussion}

A number of studies in humans and animals suggest that inflammation or infection may play a role in the pathogenesis of AMD. There is some evidence the relation between AMD and infections due to CMV, HP or CP [7-10, 23, 24]. Kalayoglu and Robman and their coworkers demonstrated that se-

Table 2. IgM and IgG Seropositivities to CP and MP (\%)

\begin{tabular}{|c|c|c|c|c|}
\hline Group & $\begin{array}{l}\text { CP IgM } \\
\text { Seropositivity (\%) }\end{array}$ & $\begin{array}{l}\text { CP IgG } \\
\text { Seropositivity (\%) }\end{array}$ & $\begin{array}{l}\text { MP IgM } \\
\quad \text { Seropositivity (\%) }\end{array}$ & $\begin{array}{l}\text { MP IgG } \\
\text { Seropositivity (\%) }\end{array}$ \\
\hline Group $1(\mathrm{n}=20)$ & $\begin{array}{l}\text { Positive: } 0(0 \%) \\
\text { Negative: } 20(100 \%)\end{array}$ & $\begin{array}{l}\text { Positive: } 0(0 \%) \\
\text { Negative: } 20(100 \%)\end{array}$ & $\begin{array}{l}\text { Positive: } 0(0 \%) \\
\text { Borderline: } 0(0 \%) \\
\text { Negative: } 20(100 \%)\end{array}$ & $\begin{array}{l}\text { Positive: } 2(10 \%) \\
\text { Borderline: } 1(5 \%) \\
\text { Negative: } 17(85 \%)\end{array}$ \\
\hline Group $2(\mathrm{n}=20)$ & $\begin{array}{l}\text { Positive: } 0(0 \%) \\
\text { Negative: } 20(100 \%)\end{array}$ & $\begin{array}{l}\text { Positive: } 2(10 \%) \\
\text { Negative: } 18(90 \%)\end{array}$ & $\begin{array}{l}\text { Positive: } 0(0 \%) \\
\text { Borderline: } 0(0 \%) \\
\text { Negative: } 20(100 \%)\end{array}$ & $\begin{array}{l}\text { Positive: } 1(5 \%) \\
\text { Borderline: } 3(15 \%) \\
\text { Negative: } 16(80 \%)\end{array}$ \\
\hline Group $3(n=20)$ & $\begin{array}{l}\text { Positive: } 0(0 \%) \\
\text { Negative: } 20(100 \%)\end{array}$ & $\begin{array}{l}\text { Positive: } 0(0 \%) \\
\text { Negative: } 20(100 \%)\end{array}$ & $\begin{array}{l}\text { Positive: } 0(0 \%) \\
\text { Borderline: } 1(5 \%) \\
\text { Negative: } 19(95 \%)\end{array}$ & $\begin{array}{l}\text { Positive: } 1(5 \%) \\
\text { Borderline: } 1(5 \%) \\
\text { Negative: } 18(90 \%)\end{array}$ \\
\hline
\end{tabular}


rum antibodies for $\mathrm{CP}$ proteins are associated with increased risk for the development and progression of AMD [7, 10]. In another study, Kalayoglu et al. demonstrated the presence of CP in AMD CNVM when compared to the eyes with AMD without CNVM and non-AMD eyes [8]. They reported that macrophages may produce VEGF after infection with $\mathrm{CP}$. In addition, Miller et al investigated the possible association between AMD and CP, HP, and CMV, as these agents are known to cause chronic infection and inflammation and CMV has been shown in animal models to accelerate the development of atherosclerosis. Miller et al found a significant association between high anti-CMV IgG titers and wet AMD compared with control and dry AMD patients. However, they did not find a difference in the distribution of titers for $\mathrm{CP}$ and HP in wet and dry AMD patients. They proposed that CMV-infected macrophages and endothelial cells might release increased amounts of proinflammatory cytokines that could cause the development of CNVM [23].

In another study, Ishida et al also found significantly elevated anti-CP IgG antibodies in patients with wet AMD compared with control subjects [24]. In contrast to these studies, two recent studies by Robman et al and Kessler et al failed to show an association between CP and AMD or AMD CNV, respectively $[9,10]$.

In our study, we expected elevation in $\mathrm{CP}$ antibodies in patients with specially wet AMD. However, distributions of $\mathrm{CP}$ antibodies were not found to be significantly different between patients with AMD and controls. These findings are contrary to those in the previous reports which demonstrated an association between CP infection and AMD. Our data supports the controversial role of CP in AMD pathogenesis.

To the best of our knowledge, this is the first report investigating the possible association between MP and AMD. In present study, we could not find a relation between AMD and MP. The insignificant results concerning with serology of MP in our study may be due to local inflammation. Thus, the histopathological or immunohistochemical studies in AMD CNVMs would be providing to understand the possible role of MP in AMD pathogenesis.

Although sample size of our study may be a limitation in this study, sufficient data to support this relationship could not be obtained. But it seems that MP or CP infection is not be related with the development of AMD. The long-term and larger studies in the series will contribute to verification of this relationship.

\section{Acknowledgments}

Those involved in conducting the study would like to thank those who assisted with the collection of data, typing, editing of manuscript, its preparation, for review, and approval of the final manuscript. The authors report no conflicts of interest in this work.

\section{References}

1. Ambati J, Ambati BK, Yoo SH, Ianchulev S, Adamis AP. Age-related macular degeneration: etiology, pathogenesis, and therapeutic strategies. Surv Ophthalmol 2003;48(3):257-293.

2. Clemons TE, Milton RC, Klein R, Seddon JM, Ferris FL, 3rd. Risk factors for the incidence of Advanced AgeRelated Macular Degeneration in the Age-Related Eye Disease Study (AREDS) AREDS report no. 19. Ophthalmology 2005;112(4):533-539.

3. Scholl HP, Fleckenstein M, Charbel Issa P, Keilhauer C, Holz FG, Weber BH. An update on the genetics of agerelated macular degeneration. Mol Vis 2007;13(196205.

4. Patel M, Chan CC. Immunopathological aspects of agerelated macular degeneration. Semin Immunopathol 2008;30(2):97-110.

5. Kijlstra A, La Heij E, Hendrikse F. Immunological factors in the pathogenesis and treatment of age-related macular degeneration. Ocul Immunol Inflamm 2005;13(1):3-11.

6. Penfold PL, Madigan MC, Gillies MC, Provis JM. Immunological and aetiological aspects of macular degeneration. Prog Retin Eye Res 2001;20(3):385-414.

7. Kalayoglu MV, Galvan C, Mahdi OS, Byrne GI, Mansour S. Serological association between Chlamydia pneumoniae infection and age-related macular degeneration. Arch Ophthalmol 2003;121(4):478-482.

8. Kalayoglu MV, Bula D, Arroyo J, Gragoudas ES, D'Amico D, Miller JW. Identification of Chlamydia pneumoniae within human choroidal neovascular membranes secondary to age-related macular degeneration. Graefes Arch Clin Exp Ophthalmol 2005;243(11):10801090 .

9. Kessler W, Jantos CA, Dreier J, Pavlovic S. Chlamydia pneumoniae is not detectable in subretinal neovascular membranes in the exudative stage of age-related macular degeneration. Acta Ophthalmol Scand 2006;84(3):333337.

10. Robman L, Mahdi OS, Wang JJ, Burlutsky G, Mitchell P, Byrne G, Guymer R, et al. Exposure to Chlamydia pneumoniae infection and age-related macular degeneration: the Blue Mountains Eye Study. Invest Ophthalmol Vis Sci 2007;48(9):4007-4011.

11. Waites KB, Talkington DF. Mycoplasma pneumoniae and its role as a human pathogen. Clin Microbiol Rev 2004;17(4):697-728, table of contents

12. Waites KB, Balish MF, Atkinson TP. New insights into the pathogenesis and detection of Mycoplasma pneumoniae infections. Future Microbiol 2008;3(6):635-648.

13. Razin S, Yogev D, Naot Y. Molecular biology and pathogenicity of mycoplasmas. Microbiol Mol Biol Rev 
1998;62(4):1094-1156.

14. Abdelrahman YM, Belland RJ. The chlamydial developmental cycle. FEMS Microbiol Rev 2005;29(5):949959.

15. Goyal P, Kalek SC, Chaudhry R, Chauhan S, Shah N. Association of common chronic infections with coronary artery disease in patients without any conventional risk factors. Indian J Med Res 2007;125(2):129-136.

16. Momiyama Y, Ohmori R, Taniguchi H, Nakamura H, Ohsuzu F. Association of Mycoplasma pneumoniae infection with coronary artery disease and its interaction with chlamydial infection. Atherosclerosis 2004;176(1):139-144.

17. Higuchi M, Castelli JB, Aiello VD, Palomino S, Reis MM, Sambiase NV, Fukasawa S, et al. Great amount of C.pneumoniae in ruptured plaque vessel segments at autopsy. A comparative study with stable plaques. Arq Bras Cardiol 2000;74(2):149-151.

18. Higuchi ML, Sambiase N, Palomino S, Gutierrez P, Demarchi LM, Aiello VD, Ramires JA. Detection of Mycoplasma pneumoniae and Chlamydia pneumoniae in ruptured atherosclerotic plaques. Braz J Med Biol Res 2000;33(9):1023-1026.

19. Ngeh J, Goodbourn C. Chlamydia pneumoniae, Mycoplasma pneumoniae, and Legionella pneumophila in elderly patients with stroke (C-PEPS, M-PEPS, L-PEPS): a case-control study on the infectious burden of atypical respiratory pathogens in elderly patients with acute cerebrovascular disease. Stroke 2005;36(2):259-265.

20. Higuchi Mde L, Higuchi-Dos-Santos MH, Pierri H, Palomino S, Sambiase NV, Ramires JA, Wajngarten M. Mycoplasma pneumoniae and Chlamydia pneumoniae in calcified nodules of aortic stenotic valves. Rev Inst Med Trop Sao Paulo 2002;44(4):209-212.

21. Stacey A, Bradlow A. Arcanobacterium haemolyticum and Mycoplasma pneumoniae co-infection. J Infect 1999;38(1):41-42.

22. Meijer A, van Der Vliet JA, Roholl PJ, Gielis-Proper SK, de Vries A, Ossewaarde JM. Chlamydia pneumoniae in abdominal aortic aneurysms: abundance of membrane components in the absence of heat shock protein 60 and DNA. Arterioscler Thromb Vasc Biol 1999;19(11):26802686.

23. Miller DM, Espinosa-Heidmann DG, Legra J, Dubovy SR, Suner IJ, Sedmak DD, Dix RD, et al. The association of prior cytomegalovirus infection with neovascular age-related macular degeneration. Am J Ophthalmol 2004;138(3):323-328.

24. Ishida O, Oku H, Ikeda T, Nishimura M, Kawagoe K, Nakamura K. Is Chlamydia pneumoniae infection a risk factor for age related macular degeneration? $\mathrm{Br} \mathrm{J}$ Ophthalmol 2003;87(5):523-524. 